\title{
Activated factor IX, factor XI and tissue factor identify patients with permanent atrial fibrillation treated with warfarin who are at risk of ischemic stroke
}

\author{
Piotr Kusak ${ }^{1}$, Danuta Czarnecka ${ }^{1}$, Matthew Gissel ${ }^{2}$, Krzysztof Plens ${ }^{3}$, Saulius Butenas ${ }^{2}$, Anetta Undas ${ }^{1}$
}

${ }^{1}$ Institute of Cardiology, Jagiellonian University School of Medicine, Krakow, Poland 2Department of Biochemistry, University of Vermont, Burlington, Vermont, USA ${ }^{3}$ Krakow Cardiovascular Research Institute, Krakow, Poland

Submitted: 12 January 2015

Accepted: 12 March 2015

Arch Med Sci 2016; 12, 5: 1000-1007

DOI: 10.5114 /aoms.2015.54791

Copyright @ 2015 Termedia \& Banach

\section{Abstract}

Introduction: Previously, we have demonstrated that significant proportions of patients with various cardiovascular diseases have active tissue factor and active factor XIa in their plasma. In the current study, we evaluated active tissue factor and active factors (F)XI and FIX in plasma from patients with atrial fibrillation.

Material and methods: In 110 consecutive patients with permanent atrial fibrillation receiving warfarin, we determined active tissue factor, together with plasma FIXa and FXIa, using clotting assays by measuring the response to inhibitory monoclonal antibodies.

Results: Sixteen (14.5\%) patients had detectable active tissue factor and active FXIa, including 11 subjects with both factors, while FIXa was observed in $28(25.7 \%)$ patients. The three positive groups did not differ from the patients without these factors with regard to demographic and clinical characteristics. Von Willebrand factor was higher in the active tissue factor-positive group $(p<0.0001)$ and FXIa-positive group $(p=0.0037)$. Individuals positive for active tissue factor and FXIa had higher plasma interleukin-6 levels ( $p=0.0014$ and 0.0322 , respectively). The presence of active tissue factor, FXIa and FIXa in anticoagulated patients with permanent atrial fibrillation correlated with elevated von Willebrand factor and interleukin-6. During a 3-year follow-up, ischemic stroke ( $n=12,10.9 \%$ ) occurred more commonly among atrial fibrillation patients who had circulating TF $(p=0.002)$ or FXIa $(p=0.013)$.

Conclusions: These data suggest that circulating active coagulation factors, in particular TF and FXIa, can be detected despite oral anticoagulation in a significant proportion of patients with atrial fibrillation, and could represent novel markers of persistent prothrombotic alterations predisposing to ischemic stroke.

Key words: anticoagulation, arrhythmia, blood coagulation, stroke.

\section{Introduction}

Atrial fibrillation (AF) is associated with a prothrombotic state and an increased risk of thromboembolic complications [1, 2]. Mechanisms underlying hypercoagulability in AF are complex and involve hemodynamic changes, endothelial damage reflected by increased von Willebrand factor (VWF) antigen, enhanced platelet activation reflected by elevated circulating levels of $\beta$-thromboglobulin [3] and P-selectin [4], increased

\author{
Corresponding author: \\ Anetta Undas MD, PhD \\ Institute of Cardiology \\ Jagiellonian University \\ Medical College \\ 80 Pradnicka St \\ 31-202 Krakow, Poland \\ Phone: +48 126143004 \\ Fax: +48 124233900 \\ E-mail: \\ mmundas@cyf-kr.edu.pl
}


thrombin generation [3] and plasma fibrinogen [4], and impaired efficiency of plasma fibrin clot lysis [5]. A coexistent low-grade inflammatory state, reflected by elevated C-reactive protein (CRP) and interleukin-6 (IL-6), contributes to AF and can promote atrial remodeling, recurrence and persistence of arrhythmia [6].

Tissue factor (TF) is a major trigger of blood coagulation in vivo. The complex of TF with factor VIla (FVIIa) activates factor IX (FIX) and factor $X(F X)$, leading to thrombin formation. It is suggested that TF is expressed in some pathological states on monocytes probably due to inflammation $[7,8]$. It has been reported that circulating plasma TF concentrations are elevated in patients with arterial hypertension, hypercholesterolemia, diabetes or coronary artery disease [9-11], but this issue is still controversial [8].

Factor Xla (FXla) is involved in the intrinsic coagulation pathway. The activation of factor XI (FXI), which occurs primarily by thrombin, leads to FIX and FX activation. Elevated FXIa has been implicated in prothrombotic states observed in acute coronary syndromes [9, 12], stable angina [13] and heart failure [12].

FIX can be activated by FXIa and the FVIIa/TF complex [14]. The activation of FX by the intrinsic factor Xase complex (FIXa bound to its cofactor, factor VIIIa) makes FIXa a potential marker of hypercoagulability. Increased FIXa activity has been observed in acute coronary syndromes [15]. To our knowledge, no reports have been published on FIXa or FXla in AF patients.

The role of TF, FXIa and FIXa as prognostic markers is unclear. In patients with prior ischemic stroke (regardless of etiology), the presence of TF and FXIa is associated with worse prognosis [16]. Chin et al. reported that elevated circulating TF is a marker of poor prognosis in heart failure [17]. Given the marked differences in assays used to quantify TF in circulating blood, determination of active TF usually indicates much less common prevalence of detectable levels of this factor in plasma.

To the best of our knowledge, TF, FXIa and FIXa assessed using coagulometric assays have not been determined in $A F$, and factors that influence plasma levels of these proteins remain obscure. We decided to verify the working hypothesis that the presence of circulating TF, FIXa and FXIa in AF, if detectable in anticoagulated subjects, might help identify persistent prothrombotic alterations in such a population. In the present study, we determined TF activity, FXIa and FIXa together with their associations with inflammatory and endothelial injury markers in patients with permanent AF. We tested the hypothesis that the presence of circulating TF, FIXa and/or FXIa in AF despite anticoagulant therapy predisposes to ischemic stroke.

\section{Material and methods}

\section{Study population}

We studied 110 consecutive patients with permanent $A F$ receiving oral anticoagulation with warfarin for more than 1 year after having screened 170 individuals with the time in the therapeutic range above $70 \%$ in the last year. We excluded patients with acute coronary syndrome within the preceding 6 months, heart failure (NYHA III/IV), hepatic dysfunction, chronic renal disease above level 3 (glomerular filtration rate less than $60 \mathrm{ml} / \mathrm{min} / 1.73 \mathrm{~m}^{2}$ ), history of venous thromboembolism or stroke, acute illness, cancer, and those who underwent surgery within the preceding month - all the conditions associated with increased thrombin generation. Coronary artery disease (CAD) was defined as a history of myocardial infarction, coronary revascularization, or hospitalization for unstable angina. Diabetes was diagnosed according to the World Health Organization criteria. Hypercholesterolemia was defined as total cholesterol $>5 \mathrm{mmol} / \mathrm{l}$, or low-density lipoprotein (LDL) cholesterol $>3.0 \mathrm{mmol} / \mathrm{l}$ or treatment with cholesterol-lowering medication. Arterial hypertension was defined according to a standard definition, i.e. systolic or diastolic pressure $\geq 140 \mathrm{~mm} \mathrm{Hg}$ or $\geq 90 \mathrm{~mm} \mathrm{Hg}$, respectively, on at least two different measurements, previous history of hypertension or current antihypertensive treatment. Heart failure was diagnosed in subjects with decreased left ventricular ejection fraction (LVEF) $<50 \%$ on echocardiography. Transthoracic echocardiography was performed in each patient using conventional techniques to measure the left atrial diameter and LVEF.

A 3-year follow-up started at the time of enrollment and was carried out on a 6-month basis by means of a visit to the center or telephone contact. None of the patients declared any interruption of warfarin use for more than 7 days. We recorded the objectively documented ischemic stroke.

The study was approved by the Ethical Committee, and all patients provided written informed consent.

\section{Laboratory methods}

Blood was drawn from an antecubital vein with minimal stasis after an overnight fast between 7 and 9 a.m. Serum and citrate plasma samples (9: 1 of $3.2 \%$ sodium citrate) were centrifuged at $2,540 \mathrm{~g}$ for $15 \mathrm{~min}$ at $24^{\circ} \mathrm{C}$ within $20 \mathrm{~min}$ of collection, immediately frozen, and stored in aliquots at $-80^{\circ} \mathrm{C}$ until further use. Lipid profiles, blood cell counts, glucose, creatinine, and International Normalized Ratio (INR) were assayed by routine laboratory techniques. High-sensitivity CRP was measured by latex nephelometry (Dade Behring, 
Marburg, Germany). Commercially available immunoenzymatic assays were used to determine plasma IL-6 (R\&D Systems, Abingdon, UK) and VWF antigen (Diagnostica Stago, Asnieres, France). All intra-assay and inter-assay coefficients of variation were below $7 \%$.

\section{Plasma clotting assays}

Plasma was thawed at $37^{\circ} \mathrm{C}$ in the presence of $0.1 \mathrm{mg} / \mathrm{ml}$ corn trypsin inhibitor (CTI; prepared as previously described) [18]. $\mathrm{CaCl}_{2}$ to a final $15 \mathrm{mM}$ concentration was added and the plasma incubated for $1 \mathrm{~min}$; clotting was initiated by the addition of $2 \mu \mathrm{M}$ phospholipid vesicles (PCPS) composed of $25 \%$ dioleoyl-sn-glycero-3-phospho-L-serine and 75\% of 1,2-dioleoyl-sn-glycero-3-phosphocholine (both from Avanti Polar Lipids, Inc; Alabaster, AL, USA) and prepared as described previously [19]. In parallel, inhibitory monoclonal anti-FXI ( $\alpha$ FXI-2), anti-FIX ( $\alpha$ FIX-91) or anti-TF ( $\alpha$ TF-5) antibodies (both produced in house) at a final $0.1 \mathrm{mg} / \mathrm{ml}$ concentration were individually added to the same plasma prior to $\mathrm{CaCl}_{2}$ addition. $\alpha \mathrm{FXI}-2$ is specific for FXI/XIa and inhibits FIX activation by FXIa [20]. $\alpha T F-5$ binds specifically to TF and interferes with TF/FVIIa complex formation [21]. Clotting times were determined using the ST8 instrument (Diagnostica Stago, Parsippany, NJ, USA). FXIa, FIXa and TF activity in plasma was calculated from calibration curves developed with human FIXa or FXla (gifts from Dr. R. Jenny from Haematologic Technologies, Inc., Essex Junction, VT, USA) or relipidated [18] $\mathrm{TF}_{1-243}$ (a gift from Dr. R. Lundblad from Baxter Healthcare Corp., Duarte, CA, USA) in pooled 10-donor normal plasma. The detectability limit for TF was 0.4 pM, for FXIa 10 pM, and for FIXa 100 pM. In 12 healthy subjects all the 3 parameters were undetectable.

\section{Statistical analysis}

Due to skewness of most variables, continuous variables are presented as median and quartiles. Categorical variables are presented as numbers and percentages. To examine differences between two independent groups, the Mann-Whitney test, Welch's $t$-test or the pooled $t$-test was used depending on normality of distributions and equality of variances of groups. The Fisher exact test was used to compare categorical variables. Odds ratios with $95 \%$ confidence intervals were computed using a logistic regression model with the presence of TF or FXla or FIXa (composite variable) as the dependent variable $[22,23]$. The same method was performed to calculate stroke predictors. Two-sided $p$-values $<0.05$ were considered statistically significant. Statistical analysis was performed with the use of JMP 9.0.0.

\section{Results}

Patient characteristics are presented in Table I. The study population was divided into groups with or without the specific coagulation factors, i.e.: $\mathrm{TF}(+)$ and $\mathrm{TF}(-), \mathrm{FXIa}(+)$ and $\mathrm{FXIa}(-), \mathrm{FIXa}(+)$ and $\mathrm{FIXa}(-)$. Age, prevalence of coronary artery disease, diabetes mellitus, heart failure, $\mathrm{CHA}_{2} \mathrm{DS}_{2}-$ VASc score along with cholesterol, glucose, creatinine, INR, and CRP were similar in the TF(+) and $\mathrm{TF}(-)$ group, the $\mathrm{FXIa}(+)$ and $\mathrm{FXIa}(-)$ group, and the $\mathrm{FIXa(+)}$ and $\mathrm{FIXa(-)}$ group.

Tissue factor - 16 (14.5\%) patients had detectable TF and the median value for only those who have > 0.4 pM TF was 1.17 pM (IQR: 0.43-2.19). Arterial hypertension was less common in the $\mathrm{TF}(+)$ group as compared to the TF(-) group. The proportion of current smokers was lower in the $\mathrm{TF}(+)$ group. In the $\mathrm{CHADS}_{2}$ score, fewer patients had 1 point in the TF(+) group. Higher levels of VWF (+31.0\%) and IL-6 (+40.1\%) were observed in the TF(+) group compared with the TF(-) group. CRP was similar in both groups (Table I).

Factor Xla - 16 (14.5\%) participants had measurable FXIa (median 77.98 pM, IQR: 30.79170.08). Both TF and FXla were observed in 11 (10\%) subjects. Current smokers was less frequently observed in the FXla(+) group. Fewer individuals in the $\mathrm{FXIa}(+)$ group had one point in the CHADS $_{2}$ score. VWF (+18.7\%) and IL-6 (+21.3\%) were higher in the $\mathrm{FXIa}(+)$ group compared with the FXIa(-) group. CRP was similar in both groups (Table I).

Factor IXa (FIXa) was observed in 28 (25.5\%) patients with a median value of $592.4 \mathrm{pM}$ (IQR: 209.0-1032.5). None of the patients had FIXa in combination with both TF and FXIa. Males were more prevalent in the FIXa(+) group. Body mass index (BMI) was higher in the FIXa(+) group. A similar proportion of patients had 2 or more points in the $\mathrm{CHADS}_{2}$ score. IL-6, VWF and CRP were similar in both groups (Table I).

The univariate logistic regression showed that a higher risk of the presence of one of the tested factors (TF, FIXa or FXIa) was observed in patients with coronary artery disease $(\mathrm{OR}=6.27 ; 95 \% \mathrm{Cl}$ : 1.85-28.9). Higher VWF (OR $=1.15$; $95 \% \mathrm{Cl}: 1.05-$ $1.27)$ and IL-6 $(\mathrm{OR}=1.29 ; 95 \% \mathrm{Cl}: 1.05-1.61)$ were also associated with a higher risk of presence of one of the tested coagulation factors (Figure 1).

Stroke - During a 3-year follow-up we recorded $12(10.9 \%)$ patients with ischemic stroke. No major bleeding events were observed; 10 patients had clinically relevant bleeding mostly from the gastrointestinal tract. The prevalence of stroke was higher in patients with diabetes, heart failure and in patients with two or more points in the $\mathrm{CHADS}_{2}$ score (Table II). Higher levels of VWF $(+18.4 \%)$, D-dimer $(+51.1 \%)$, and fibrinogen $(+27.4 \%)$ were 
Table I. Characteristics of patients with chronic atrial fibrillation

\begin{tabular}{|c|c|c|c|c|c|c|c|}
\hline Variable & $N=110$ & $\begin{array}{c}\mathrm{TF}(+) \\
n=16\end{array}$ & $\begin{array}{c}\mathrm{TF}(-) \\
n=94\end{array}$ & $\begin{array}{c}\mathrm{FXIa}(+) \\
n=16\end{array}$ & $\begin{array}{l}\mathrm{FXIa}(-) \\
n=94\end{array}$ & $\begin{array}{l}\mathrm{FIXa}(+) \\
n=28\end{array}$ & $\begin{array}{l}\mathrm{FIXa}(-) \\
n=81\end{array}$ \\
\hline Age [ & $\begin{array}{c}63.0 \\
(55.0 ; 70.0)\end{array}$ & $\begin{array}{c}60.0 \\
(52.0 ; 67.8)\end{array}$ & $\begin{array}{c}63.0 \\
(56.0 ; 70.3)\end{array}$ & $\begin{array}{c}57.0 \\
(50.3 ; 69.8)\end{array}$ & $\begin{array}{c}63.5 \\
(56.8 ; 70.0)\end{array}$ & $\begin{array}{c}61.5 \\
(53.3 ; 66.8)\end{array}$ & $\begin{array}{c}64.0 \\
(55.0 ; 71.5)\end{array}$ \\
\hline $\begin{array}{l}\text { Male gender, } \\
n(\%)\end{array}$ & $57(51.8)$ & $8(50.0)$ & $49(52.1)$ & $7(43.8)$ & $50(53.2)$ & $20(71.4)^{\star}$ & 37 (45.7) \\
\hline $\mathrm{BMI}\left[\mathrm{kg} / \mathrm{m}^{2}\right]$ & $\begin{array}{c}29.1 \\
(26.6 ; 31.4)\end{array}$ & $\begin{array}{c}30.7 \\
(26.9 ; 32.2)\end{array}$ & $\begin{array}{c}29.0 \\
(26.3 ; 31.2)\end{array}$ & $\begin{array}{c}27.1 \\
(25.1 ; 32.0)\end{array}$ & $\begin{array}{c}29.2 \\
(26.8 ; 31.2)\end{array}$ & $\begin{array}{c}31.8 \\
(26.4 ; 35.5)^{\star}\end{array}$ & $\begin{array}{c}28.4 \\
(26.6 ; 30.6)\end{array}$ \\
\hline $\begin{array}{l}\text { Hypertension, } \\
n(\%)\end{array}$ & $65(59.1)$ & $4(25.0)^{*}$ & $61(64.9)$ & $6(37.5)$ & $59(62.8)$ & $19(67.9)$ & $46(56.8)$ \\
\hline $\mathrm{CAD}, n(\%)$ & 15 (13.6) & $3(18.8)$ & $12(12.8)$ & $4(25.0)$ & $11(11.7)$ & $7(25.0)$ & $8(9.9)$ \\
\hline $\begin{array}{l}\text { Diabetes, } \\
n(\%)\end{array}$ & $6(5.5)$ & $2(12.5)$ & $4(4.3)$ & $2(12.5)$ & $4(4.3)$ & $1(3.6)$ & $5(6.2)$ \\
\hline $\begin{array}{l}\text { Heart failure, } \\
n(\%)\end{array}$ & $20(18.2)$ & $1(6.3)$ & $19(20.2)$ & $1(6.3)$ & $19(20.2)$ & $7(25.0)$ & $13(16.0)$ \\
\hline $\begin{array}{l}\text { Smoking, } \\
n(\%)\end{array}$ & $44(40.0)$ & $2(12.5)^{\star}$ & $42(44.7)$ & $2(12.5)^{\star}$ & $42(44.7)$ & $10(35.7)$ & $34(42.0)$ \\
\hline $\begin{array}{l}\mathrm{CHADS}_{2} \\
\geq 2 \text { points }\end{array}$ & $27(24.5)$ & $3(18.8)$ & $25(25.5)$ & $4(25.0)$ & $23(24.5)$ & $7(25.0)$ & $20(24.7)$ \\
\hline $\begin{array}{l}\mathrm{CHADS}_{2} \\
1 \text { point }\end{array}$ & $(42.7)$ & $2(12.5)^{\star}$ & 45 (47.9) & $2(12.5)^{\star}$ & $45(47.9)$ & $15(53.6)$ & $32(39.5)$ \\
\hline $\begin{array}{l}\mathrm{CHA}_{2} \mathrm{DS}_{2}-\mathrm{VASC} \\
\geq 2 \text { points, } \\
n(\%)\end{array}$ & $64(58.2)$ & $5(31.3)^{*}$ & $59(62.8)$ & $6(37.5)$ & $58(61.7)$ & $16(57.1)$ & $48(59.3)$ \\
\hline $\begin{array}{l}\mathrm{CHA}_{2} \mathrm{DS}_{2}-\mathrm{VASC} \\
1 \text { point, } n(\%)\end{array}$ & $37(33.6)$ & $9(56.3)^{\star}$ & $28(29.8)$ & $8(50.0)$ & $29(30.9)$ & $9(32.1)$ & $27(33.3)$ \\
\hline Aspirin, $n(\%)$ & $35(31.8)$ & $9(56.2)^{\star}$ & $26(27.7)$ & $12(75.0)^{*}$ & $23(24.5)$ & $12(42.9)$ & $22(27.2)$ \\
\hline Statin & $53(48.2)$ & $1(6.3)^{\star}$ & $52(55.3)$ & $4(25.0)$ & $49(52.1)$ & $10(35.7)$ & $43(53.1)$ \\
\hline $\begin{array}{l}\text { Total } \\
\text { cholesterol } \\
{[\mathrm{mM}]}\end{array}$ & $\begin{array}{c}5.05 \\
(4.17 ; 5.62)\end{array}$ & $\begin{array}{c}5.01 \\
(4.62 ; 5.89)\end{array}$ & $\begin{array}{c}5.05 \\
(4.01 ; 5.61)\end{array}$ & $\begin{array}{c}4.83 \\
(4.05 ; 5.49)\end{array}$ & $\begin{array}{c}5.08 \\
(4.18 ; 5.65)\end{array}$ & $\begin{array}{c}5.25 \\
(3.91 ; 5.87)\end{array}$ & $\begin{array}{c}5.03 \\
(4.19 ; 5.59)\end{array}$ \\
\hline $\begin{array}{l}\text { LDL } \\
\text { cholesterol } \\
{[\mathrm{mM}]}\end{array}$ & $\begin{array}{c}2.91 \\
(2.36 ; 3.40)\end{array}$ & $\begin{array}{c}3.02 \\
(2.51 ; 3.38)\end{array}$ & $\begin{array}{c}2.86 \\
(2.36 ; 3.40)\end{array}$ & $\begin{array}{c}3.00 \\
(2.34 ; 3.10)\end{array}$ & $\begin{array}{c}2.86 \\
(2.38 ; 3.43)\end{array}$ & $\begin{array}{c}2.95 \\
(2.22 ; 3.79)\end{array}$ & $\begin{array}{c}2.88 \\
(2.41 ; 3.36)\end{array}$ \\
\hline $\begin{array}{l}\text { HDL } \\
\text { cholesterol } \\
{[\mathrm{mM}]}\end{array}$ & $\begin{array}{c}1.46 \\
(1.14 ; 1.70)\end{array}$ & $\begin{array}{c}1.61 \\
(1.21 ; 1.74)\end{array}$ & $\begin{array}{c}1.44 \\
(1.14 ; 1.69)\end{array}$ & $\begin{array}{c}1.56 \\
(1.00 ; 1.69)\end{array}$ & $\begin{array}{c}1.45 \\
(1.18 ; 1.71)\end{array}$ & $\begin{array}{c}1.46 \\
(1.15 ; 1.72)\end{array}$ & $\begin{array}{c}1.45 \\
(1.14 ; 1.70)\end{array}$ \\
\hline $\begin{array}{l}\text { Triglycerides } \\
{[\mathrm{mM}]}\end{array}$ & $\begin{array}{c}1.15 \\
(0.74 ; 1.66)\end{array}$ & $\begin{array}{c}1.43 \\
(0.64 ; 1.93)\end{array}$ & $\begin{array}{c}1.13 \\
(0.75 ; 1.58)\end{array}$ & $\begin{array}{c}1.17 \\
(0.62 ; 1.67)\end{array}$ & $\begin{array}{c}1.13 \\
(0.75 ; 1.66)\end{array}$ & $\begin{array}{c}0.94 \\
(0.67 ; 1.63)\end{array}$ & $\begin{array}{c}1.17 \\
(0.78 ; 1.69)\end{array}$ \\
\hline $\begin{array}{l}\text { Glucose } \\
{[\mathrm{mM}]}\end{array}$ & $\begin{array}{c}4.90 \\
(4.50 ; 5.20)\end{array}$ & $\begin{array}{c}4.95 \\
(4.53 ; 5.40)\end{array}$ & $\begin{array}{c}4.87 \\
(4.50 ; 5.20)\end{array}$ & $\begin{array}{c}4.85 \\
(4.43 ; 5.30)\end{array}$ & $\begin{array}{c}4.90 \\
(4.51 ; 5.20)\end{array}$ & $\begin{array}{c}4.85 \\
(4.43 ; 5.08)\end{array}$ & $\begin{array}{c}4.90 \\
(4.51 ; 5.25)\end{array}$ \\
\hline $\begin{array}{l}\text { Creatinine } \\
{[\mu \mathrm{M}]}\end{array}$ & $\begin{array}{c}70.7 \\
(60.8 ; 80.3)\end{array}$ & $\begin{array}{c}72.5 \\
(58.0 ; 85.8)\end{array}$ & $\begin{array}{c}70.7 \\
(61.0 ; 79.7)\end{array}$ & $\begin{array}{c}62.5 \\
(50.8 ; 84.0)\end{array}$ & $\begin{array}{c}70.7 \\
(61.9 ; 80.3)\end{array}$ & $\begin{array}{c}69.5 \\
(60.0 ; 79.8)\end{array}$ & $\begin{array}{c}69.5 \\
(60.0 ; 79.8)\end{array}$ \\
\hline INR & $\begin{array}{c}2.48 \\
(2.25 ; 2.83)\end{array}$ & $\begin{array}{c}2.50 \\
(2.20 ; 2.78)\end{array}$ & $\begin{array}{c}2.45 \\
(2.25 ; 2.84)\end{array}$ & $\begin{array}{c}2.60 \\
(2.39 ; 2.92)\end{array}$ & $\begin{array}{c}2.44 \\
(2.20 ; 2.75)\end{array}$ & $\begin{array}{c}2.40 \\
(2.08 ; 2.72)\end{array}$ & $\begin{array}{c}2.49 \\
(2.30 ; 2.85)\end{array}$ \\
\hline VWF (\%) & $\begin{array}{c}210.5 \\
(169.0 ; 240.3\end{array}$ & $\begin{array}{c}271.0 \\
51.0 ; 279.0)\end{array}$ & $\begin{array}{c}196.5 \\
168.0 ; 231.3\end{array}$ & $\begin{array}{c}253.0 \\
192.8 ; 278.8\end{array}$ & $\begin{array}{c}205.5 \\
(168.0 ; 235 .\end{array}$ & $\begin{array}{c}222.0 \\
168.5 ; 235.8\end{array}$ & $\begin{array}{c}202.0 \\
(169.0 ; 245.5)\end{array}$ \\
\hline CRP $[\mathrm{mg} / \mathrm{l}]$ & $\begin{array}{c}2.96 \\
(1.89 ; 4.44)\end{array}$ & $\begin{array}{c}2.35 \\
(1.20 ; 4.13)\end{array}$ & $\begin{array}{c}3.01 \\
(1.92 ; 4.70)\end{array}$ & $\begin{array}{c}2.23 \\
(1.20 ; 4.13)\end{array}$ & $\begin{array}{c}3.01 \\
(1.98 ; 4.51)\end{array}$ & $\begin{array}{c}3.12 \\
(2.08 ; 5.29)\end{array}$ & $\begin{array}{c}2.98 \\
(1.83 ; 4.42)\end{array}$ \\
\hline IL-6 [pg/ml] & $\begin{array}{c}5.55 \\
(4.40 ; 7.03)\end{array}$ & $\begin{array}{c}7.65 \\
(5.50 ; 9.88)^{\star}\end{array}$ & $\begin{array}{c}5.40 \\
(4.30 ; 6.70)\end{array}$ & $\begin{array}{c}6.30 \\
(5.30 ; 9.33)^{\star}\end{array}$ & $\begin{array}{c}5.40 \\
(4.30 ; 6.83)\end{array}$ & $\begin{array}{c}5.40 \\
(4.23 ; 7.08)\end{array}$ & $\begin{array}{c}5.60 \\
(4.45 ; 6.75)\end{array}$ \\
\hline LVEF (\%) & $\begin{array}{c}49.0 \\
(41.2 ; 55.0)\end{array}$ & $\begin{array}{c}52.1 \\
(41.5 ; 59.7)\end{array}$ & $\begin{array}{c}47.9 \\
(40.9 ; 55.0)\end{array}$ & $\begin{array}{c}53.0 \\
(43.3 ; 59.7)\end{array}$ & $\begin{array}{c}47.9 \\
(40.4 ; 55.0)\end{array}$ & $\begin{array}{c}51.0 \\
(42.4 ; 57.9)\end{array}$ & $\begin{array}{c}48.0 \\
(40.8 ; 53.4)\end{array}$ \\
\hline $\mathrm{LA}[\mathrm{mm}]$ & $\begin{array}{c}43.0 \\
(40.0 ; 46.0)\end{array}$ & $\begin{array}{c}44.5 \\
(42.3 ; 52.8)^{\star}\end{array}$ & $\begin{array}{c}43.0 \\
(40.0 ; 45.0)\end{array}$ & $\begin{array}{c}42.5 \\
(38.5 ; 44.8)\end{array}$ & $\begin{array}{c}43.0 \\
(40.0 ; 46.0)\end{array}$ & $\begin{array}{c}43.5 \\
(40.0 ; 47.0)\end{array}$ & $\begin{array}{c}43.0 \\
(40.5 ; 45.0)\end{array}$ \\
\hline
\end{tabular}

Values are presented as median and quartiles or as percentages. *Values of $p<0.05$ versus a subgroup without the factor tested. 


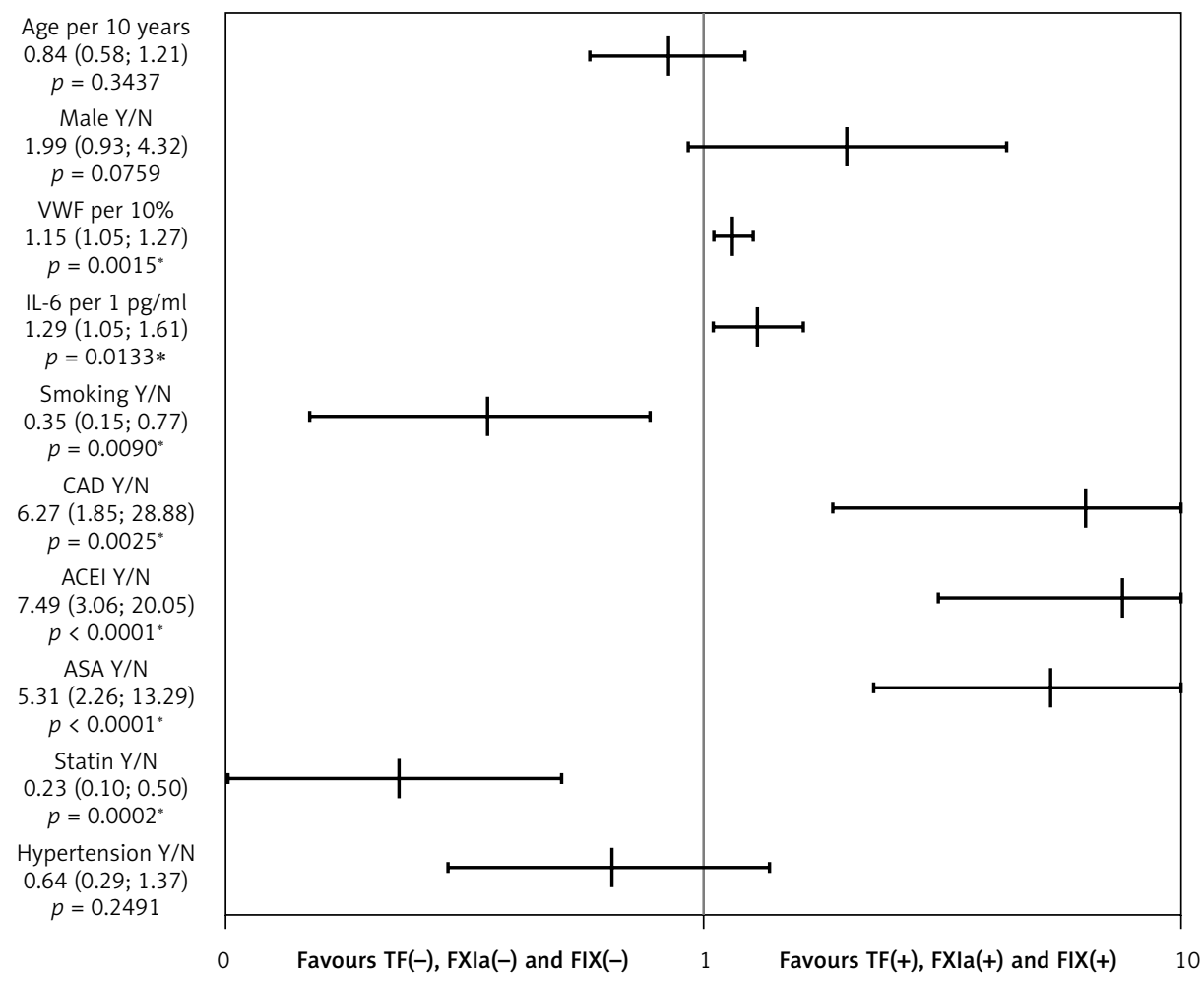

Figure 1. Univariate logistic regression analyses for the presence of active tissue factor (TF), activated factor $X I$ (FXIa) or factor IX (FIXa). Detection of TF, FIXa or FXIa in anticoagulated patients with permanent atrial fibrillation is predicted by elevated VWF, IL-6, CAD, use of ACEI and/or aspirin, while current smoking and statin use are associated with the absence of any of these factors in circulating blood

The graph with logarithmic scale shows point estimates of odds ratios with 95\% confidence intervals. vWF - von Willebrand factor, IL-6 - interleukin-6, CAD - coronary artery disease, ASA - aspirin, ACEI - angiotensin-converting enzyme inhibitor, F- factor. ${ }^{*} p<0.05$.

observed in patients who experienced stroke. As expected, time in therapeutic range (TTR) $(-27.4 \%)$ was lower in patients with stroke (Table II). Importantly, TF and FXIa were present more commonly among the patients with stroke despite warfarin use $(\mathrm{OR}=8.80,95 \% \mathrm{Cl}: 2.36-33.67$, and $\mathrm{OR}=5.65$, 95\% Cl: 1.46-21.02, respectively) (Figure 2). FIXa tended to be more prevalent among patients with stroke $(p=0.07)$ (Table II). In the multivariate logistic regression model the independent predictors of stroke in AF patients while on warfarin were heart failure, treatment with angiotensin-converting enzyme inhibitor (ACEI) and the presence of active TF after adjustment for TTR.

\section{Discussion}

Our data indicate that TF, FXIa and FIXa are observed in a substantial proportion of anticoagulated AF patients. Permanent AF per se is a pathological state in which despite warfarin therapy enhanced blood coagulation reflected by the presence of active TF, FXIa and FIXa can be observed. The appearance of these factors is independent from INR values. Butenas et al. showed that CAD leads to increased levels of plasma active TF and FXIa and inflammatory cytokines are involved in this phenomenon [9]. In hypertensive individuals higher TF [10] and FIXa [24] have been observed. AF itself, being a hypercoagulable state, in association with diabetes enhances prothrombotic alterations, because it is known that diabetes is characterized by increased amounts of circulating TF, fibrinogen, and thrombin formation markers [2527]. In search for determinants of the presence of active TF, FXI and FIXa in AF patients, we found that $C A D$ is associated with the presence of one of the tested factors. One might speculate that this factor may contribute to the progression of this disease. We failed to observe any correlation between the three factors and diabetes. Unexpectedly, in the $T F(+)$ group, hypertensive patients were underrepresented compared with the TF(-) group. Hypercholesterolemia has been suggested to induce TF expression, and statin treatment may reduce active TF in circulating blood $[11,28]$. In our study, a substantial proportion of AF patients without TF were treated with statins. However, it should be stressed that statin intake characterizes patients at higher cardiovascular and thromboembolic risk. A novel finding is an association of VWF with the presence of active TF and FXIa in AF patients. Increased plasma VWF that results 
Activated factor IX, factor $\mathrm{XI}$ and tissue factor identify patients with permanent atrial fibrillation treated with warfarin who are at risk of ischemic stroke

Table II. Characteristics of atrial fibrillation patients with and without stroke incidence during 3-year follow-up

\begin{tabular}{|c|c|c|c|}
\hline \multirow[t]{2}{*}{ Variable } & \multicolumn{2}{|c|}{ Stroke } & \multirow[t]{2}{*}{$P$-value } \\
\hline & Absent $(N=98,89.1 \%)$ & Present $(N=12,10.9 \%)$ & \\
\hline Diabetes, $n(\%)$ & $3(3.1)$ & $3(25.0)$ & 0.017 \\
\hline Heart failure, $n(\%)$ & $14(14.3)$ & $6(50.0)$ & 0.008 \\
\hline ACEI, $n(\%)$ & $25(25.5)$ & $9(75.0)$ & 0.001 \\
\hline Fibrinogen $[\mathrm{g} / \mathrm{l}]$ & $4.00(2.38 ; 4.83)$ & $4.38(3.91 ; 5.16)$ & 0.04 \\
\hline VWF (\%) & $201.5(168.0 ; 236.8)$ & $238.5(210.8 ; 278.0)$ & 0.006 \\
\hline D-dimer [ng/ml] & $215.0(154.8 ; 277.5)$ & $317.0(287.5 ; 404.0)$ & 0.0001 \\
\hline TF present, $n(\%)$ & $10(10.2)$ & $6(50.0)$ & 0.002 \\
\hline FXla present, $n(\%)$ & $11(11.2)$ & $5(41.7)$ & 0.015 \\
\hline FIXa present, $n(\%)$ & $22(22.7)$ & $6(50.0)$ & 0.073 \\
\hline FIXa, FXIa or TF present, $n(\%)$ & $37(37.8)$ & $12(100)$ & $<0.0001$ \\
\hline Time in therapeutic range (\%) & $75.0(65.0 ; 85.0)$ & $55.0(45.0 ; 60.0)$ & $<0.0001$ \\
\hline $\begin{array}{l}\text { CHADS }_{2} \\
1 \text { point, } n \text { (\%) }\end{array}$ & $47(48.0)$ & $0(0.0)$ & 0.0011 \\
\hline $\begin{array}{l}\mathrm{CHADS}_{2} \\
\geq 2 \text { points, } n(\%)\end{array}$ & $18(18.4)$ & $9(75.0)$ & 0.0001 \\
\hline
\end{tabular}

Abbreviations see Table I. ACEI - angiotensin-converting enzyme inhibitor.

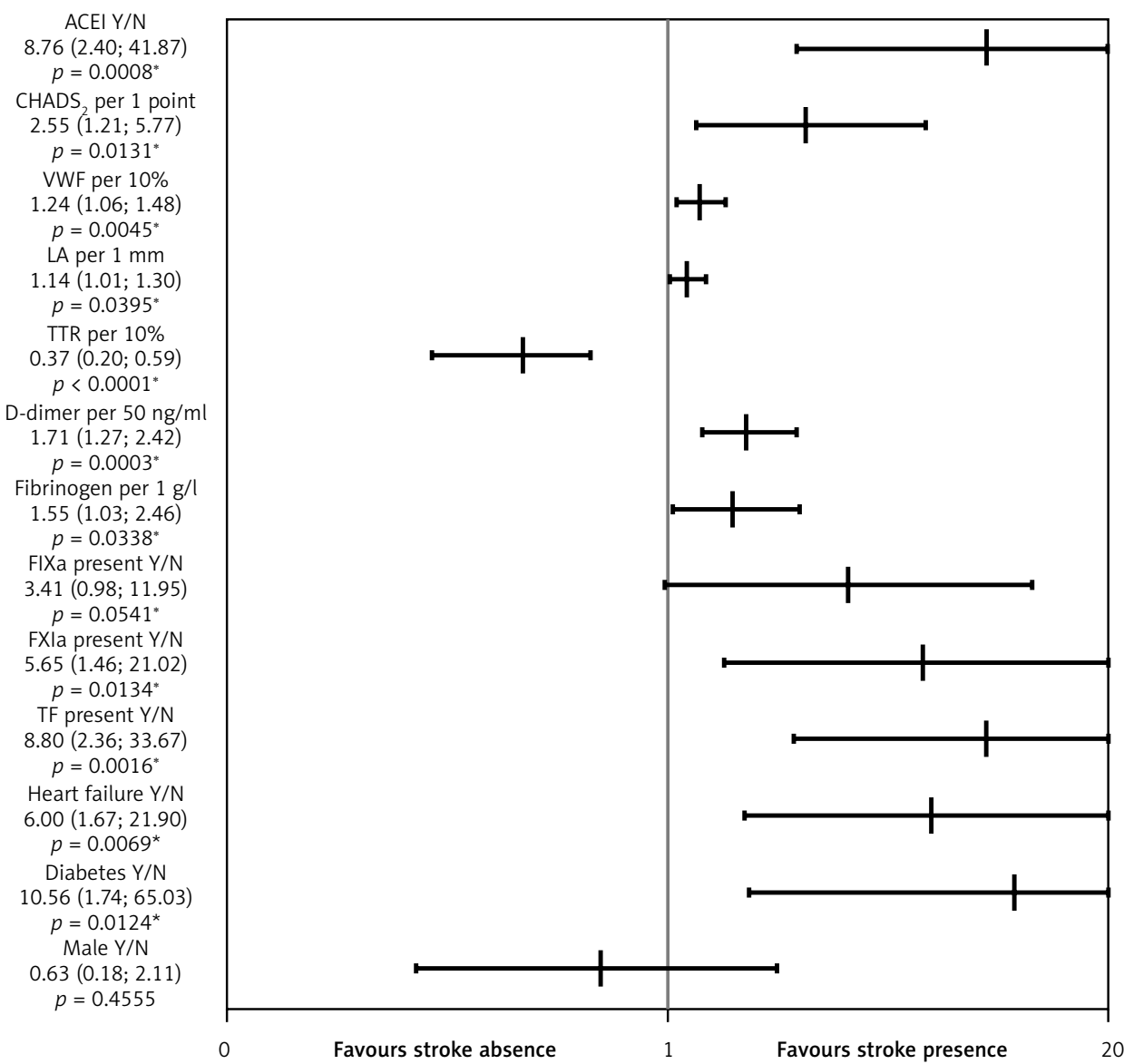

Figure 2. Univariate logistic regression analyses for ischemic stroke in anticoagulated patients with permanent atrial fibrillation during follow-up. Stroke is associated with the use of ACEI, higher CHADS2 score, vWF, D-dimer, fibrinogen, coexisting diabetes type 2 or heart failure, and detection of TF, or FXIa at enrolment. Only higher TTR is associated with low stroke risk

The graph with logarithmic scale shows point estimates of odds ratios with $95 \%$ confidence intervals. ACEI - angiotensinconverting enzyme inhibitor, VWF - von Willebrand factor, LA - left atrium size, TTR - time in therapeutic range, F-factor. ${ }^{*} p<0.05$. 
from endothelial damage has been demonstrated to predict cardiovascular events including stroke in $\mathrm{AF}$ [29]. It originates from damaged endothelial cells but in AF mostly from atrial endothelial cells [30]. The current findings provide additional evidence that there is a correlation between endothelial dysfunction and prothrombotic state reflected by the activity of TF and FXI in AF and this link is present despite oral anticoagulation.

Our data showed that IL- 6 was higher in anticoagulated AF patients with detectable TF or FXIa. It is well known that inflammation is associated with $\mathrm{AF}$, and ongoing inflammation can predispose to AF. Moreover, structural heart diseases can promote inflammation, and inflammatory markers are increased in this arrhythmia [31-33]. Since IL- 6 failed to be shown as an independent predictor of the presence of TF or FXIa in our patients, it might be speculated that in permanent AF during warfarin administration inflammation has a minor effect on the generation and persistence of active TF and FXIa.

To our knowledge, our study is the first to show the presence of circulating plasma FIXa in chronic $A F$ and characterizes factors associated with the presence of circulating TF or FXla. The current study suggests that regulation of FIXa formation and persistence in circulating blood differ from the mechanisms and associations observed for active TF and FXIa in AF patients. Due to the paucity of data on FIXa in the plasma of cardiovascular patients, its role in blood coagulation merits further investigations.

We observed that stroke occurs more commonly among anticoagulated AF patients who had circulating TF and FXla at enrollment. This novel finding suggests that the two coagulation factors present on warfarin, together with low quality of anticoagulation, heart failure and diabetes, predispose to ischemic complications of AF during follow-up. Larger studies are needed to validate this observation.

Several study limitations should be acknowledged. The small number of the patients studied especially in subgroups hampers the data interpretation. A larger cohort is needed to confirm our observations. There was no control 'disease' group with sinus rhythm; therefore we cannot exclude a potential impact of coexisting cardiovascular diseases or medications on the presence of circulating TF, FXIa or FIXa. Since transesophageal echocardiography was not performed, we cannot exclude the presence of a thrombus within the left atrium appendage, which might increase hypercoagulability including circulating TF. Longterm follow-up with clinical outcomes is needed to evaluate the potential predictive value of active TF, FXIa, or FIXa in thromboembolic risk associated with permanent AF. It remains to be established whether new oral thrombin and FXa inhibitors, which are now widely used in AF, can more effectively suppress formation of active TF, FXla, and FIXa [34, 35]. A role of these factors, particularly TF, cannot be ruled out also in other cardiovascular diseases, e.g. abdominal aneurysm [36].

In conclusion, the present study showed the presence of TF, FXIa and FIXa in anticoagulated patients with permanent AF. VWF and IL- 6 have been identified as laboratory determinants of the presence of those active coagulation factors in this AF patient population despite anticoagulation. It is tempting to speculate that TF, FXIa and FIXa might be considered as novel markers of thromboembolic risk in $A F$, which can be detected even during warfarin therapy.

\section{Acknowledgments}

We thank Dr. Richard Jenny for providing FIXa and FXIa and Dr. Roger Lundblad for providing $\mathrm{TF}_{1-243}$. We also thank Ruhin Yuridullah for his technical assistance and Kamil Fijorek for his contribution to the statistical analysis.

This work was supported by grants from the National Institutes of Health (HL46703; to S.B.), and from Jagiellonian University (K/ZDS/002936; to A.U.).

The publication of this article was supported by Faculty of Medicine, Jagiellonian University Medical College, Leading national research Centre (KNOW) 2012-2017.

\section{Conflict of interest}

The authors declare no conflict of interest.

\section{References}

1. Wolf PA, Dawber TR, Thomas HE Jr., Kannel WB. Epidemiologic assessment of chronic atrial fibrillation and risk of stroke: the Framingham study. Neurology 1978; 28: 973-7.

2. Wolf PA, Abbott RD, Kannel WB. Atrial fibrillation as an independent risk factor for stroke: the Framingham Study. Stroke 1991; 22: 983-8.

3. Feinberg WM, Pearce LA, Hart RG, et al. Markers of thrombin and platelet activity in patients with atrial fibrillation: correlation with stroke among 1531 participants in the stroke prevention in atrial fibrillation III study. Stroke 1999; 30: 2547-53.

4. Fu R, Wu S, Wu P, Qiu J. A study of blood soluble P-selectin, fibrinogen, and von Willebrand factor levels in idiopathic and lone atrial fibrillation. Europace 2011; 13: 31-6.

5. Zabczyk M, Majewski J, Lelakowski J. Thromboembolic events are associated with prolonged clot lysis time in patients with permanent atrial fibrillation. Pol Arch Med Wewn 2011; 121: 400-7.

6. Chung MK, Martin DO, Sprecher D, et al. C-reactive protein elevation in patients with atrial arrhythmias: inflammatory mechanisms and persistence of atrial fibrillation. Circulation 2001; 104: 2886-91. 
7. Steffel J, Luscher TF, Tanner FC. Tissue factor in cardiovascular diseases: molecular mechanisms and clinical implications. Circulation 2006; 113: 722-31.

8. Butenas S, Orfeo T, Mann KG. Tissue factor in coagulation: Which? Where? When? Arterioscler Thromb Vasc Biol 2009; 29: 1989-96.

9. Butenas S, Undas A, Gissel MT, Szuldrzynski K, Zmudka K, Mann KG. Factor Xla and tissue factor activity in patients with coronary artery disease. Thromb Haemost 2008; 99: 142-9.

10. Felmeden DC, Spencer CG, Chung NA, et al. Relation of thrombogenesis in systemic hypertension to angiogenesis and endothelial damage/dysfunction (a substudy of the Anglo-Scandinavian Cardiac Outcomes Trial [ASCOT]). Am J Cardiol 2003; 92: 400-5.

11. Drake TA, Hannani K, Fei HH, Lavi S, Berliner JA. Minimally oxidized low-density lipoprotein induces tissue factor expression in cultured human endothelial cells. Am J Pathol 1991; 138: 601-7.

12. Zabczyk M, Butenas S, Palka I, Nessler J, Undas A. Active tissue factor and activated factor XI in circulating blood of patients with systolic heart failure due to ischemic cardiomyopathy. Pol Arch Med Wewn 2010; 120: 334-40.

13. Zabczyk M, Butenas S, Plicner D, Fijorek K, Sadowski J, Undas A. Factors associated with the presence of circulating active tissue factor and activated factor XI in stable angina patients. Blood Coagul Fibrinolysis 2012; 23: 189-94.

14. Howard EL, Becker KC, Rusconi CP, Becker RC. Factor IXa inhibitors as novel anticoagulants. Arterioscler Thromb Vasc Biol 2007; 27: 722-7.

15. Minnema MC, Peters RJ, de Winter R, et al. Activation of clotting factors XI and IX in patients with acute myocardial infarction. Arterioscler Thromb Vasc Biol 2000; 20: 2489-93.

16. Undas A, Slowik A, Gissel M, Mann KG, Butenas S. Circulating activated factor $\mathrm{XI}$ and active tissue factor as predictors of worse prognosis in patients following ischemic cerebrovascular events. Thromb Res 2011; 128: e62-6.

17. Chin BS, Blann AD, Gibbs CR, Chung NA, Conway DG, Lip GY. Prognostic value of interleukin-6, plasma viscosity, fibrinogen, von Willebrand factor, tissue factor and vascular endothelial growth factor levels in congestive heart failure. Eur J Clin Invest 2003; 33: 941-8.

18. Cawthern KM, van 't Veer C, Lock JB, DiLorenzo ME, Branda RF, Mann KG. Blood coagulation in hemophilia A and hemophilia C. Blood 1998; 91: 4581-92.

19. Higgins DL, Mann KG. The interaction of bovine factor $\mathrm{V}$ and factor $\mathrm{V}$-derived peptides with phospholipid vesicles. J Biol Chem 1983; 258: 6503-8.

20. Butenas S, Dee JD, Mann KG. The function of factor XI in tissue factor-initiated thrombin generation. J Thromb Haemost 2003; 1: 2103-11.

21. Parhami-Seren B, Butenas S, Krudysz-Amblo J, Mann KG. Immunologic quantitation of tissue factors. J Thromb Haemost 2006; 4: 1747-55.

22. Heinze G, Schemper M. A solution to the problem of separation in logistic regression. Stat Med 2002; 21: 2409-19.

23. Fijorek K, Sokołowski A. Separation-resistant and bias-reduced logistic regression: Statistica macro. J Stat Softw 2012; 47.

24. Agorasti A, Mourvati E, Trivellas T. Changes in haemo static and platelet activation markers in non-dipper hy pertensive patients. Int Urol Nephrol 2012; 44: 523-33.

25. Undas A, Slowik A, Gissel M, Mann KG, Butenas S. AC tive tissue factor and activated factor $\mathrm{XI}$ in patients with acute ischemic cerebrovascular events. Eur J Clin Invest 2012; 42: 123-9.

26. Vaidyula VR, Rao AK, Mozzoli M, Homko C, Cheung P, Boden G. Effects of hyperglycemia and hyperinsulinemia on circulating tissue factor procoagulant activity and platelet CD40 ligand. Diabetes 2006; 55: 202-8.

27. Morishita E, Asakura H, Jokaji H, et al. Hypercoagulability and high lipoprotein(a) levels in patients with type II diabetes mellitus. Atherosclerosis 1996; 120: 7-14.

28. Owens AP 3rd, Passam FH, Antoniak S, et al. Monocyte tissue factor-dependent activation of coagulation in hypercholesterolemic mice and monkeys is inhibited by simvastatin. J Clin Invest 2012; 122: 558-68.

29. Conway DS, Pearce LA, Chin BS, Hart RG, Lip GY. Plasma von Willebrand factor and soluble $p$-selectin as indices of endothelial damage and platelet activation in 1321 patients with nonvalvular atrial fibrillation: relationship to stroke risk factors. Circulation 2002; 106: 1962-7.

30. Watson T, Shantsila E, Lip GY. Mechanisms of thrombogenesis in atrial fibrillation: Virchow's triad revisited. Lancet 2009; 373: 155-66.

31. You L, Wang P, Lv J, Cianflone K, Wang D, Zhao C. The role of high-sensitivity C-reactive protein, interleukin- 6 and cystatin $\mathrm{C}$ in ischemic stroke complicating atrial fibrillation. J Huazhong Univ Sci Technolog Med Sci 2010; 30: 648-51.

32. Ellinor PT, Low A, Patton KK, Shea MA, MacRae CA. C-Reactive protein in lone atrial fibrillation. Am J Cardiol 2006; 97: 1346-50.

33. Conway DS, Buggins P, Hughes E, Lip GY. Relationship of interleukin- 6 and C-reactive protein to the prothrombotic state in chronic atrial fibrillation. J Am Coll Cardiol 2004; 43: 2075-82.

34. Undas A, Pasierski T, Windyga J, Crowther M. Practical aspects of new oral anticoagulant use in atrial fibrillation. Pol Arch Med Wewn 2014; 124: 124-35.

35. Gorczyca-Michta I, Wożakowska-Kapłon B. New oral anticoagulants - will they be used with antiplatelet drugs in patients with atrial fibrillation after acute coronary syndrome? Postep Kardiol Inter 2013; 9: 348-52.

36. Skora J, Dawiskiba T, Zaleska P, et al. Prognostic value of tissue factor in patients with abdominal aortic and iliac arterial aneurysms - preliminary study. Arch Med Sci 2013; 9: 1071-7. 